\title{
LIMITAÇÕES INFRACONSTITUCIONAIS AOS DIREITOS FUNDAMENTAIS
}

\author{
FUNDAMENTAL RIGHTS RESTRICTIONS
}

\author{
Orlando Luiz Zanon Junior ${ }^{1}$
}

\begin{abstract}
RESUMO
É insubsistente a distinção entre normas meramente reguladoras e restritivas de direitos fundamentais, porquanto qualquer conformação representa alguma contenção, ainda que em intensidade ínfima, ao direito fundamental respectivo ou a outros que com ele possam colidir, salvo se o preceito for mera reprodução do conteúdo constitucional das prerrogativas envolvidas sob outra roupagem. Considerando tal premissa (inexistência de normas infraconstitucionais não-restritivas de direitos fundamentais), conclui-se que o legislador pode impor contornos aos direitos fundamentais, ainda que sem autorização constitucional expressa para tanto, estabelecendo as chamadas restrições implícitas, desde que fundado em outros preceitos constitucionais. Para superação da problemática quanto ao controle da atividade legiferante restritiva, foram desenvolvidas duas proposições teóricas predominantes: segundo a teoria absoluta do conteúdo essencial, cada direito fundamental possui uma parcela nuclear indelével e irrestringível, porquanto protegida por uma barreira intransponível, enquanto, de outro lado, a teoria relativa do conteúdo essencial propõe que o núcleo central dos direitos depende das peculiaridades da situação fática e das prerrogativas fundamentais envolvidas, firmando-se diferentemente em cada caso concreto, mediante sopesamento fundamentado.
\end{abstract}

Palavras-chave: Direitos fundamentais .Restrições. Suporte fático.

Proporcionalidade. Núcleo essencial.

\begin{abstract}
It is ineffectual to distinguish between purely regulatory and restrictive law, as any conformation represents some restraint, even in very small intensity, to the fundamental right concerned or to others which might collide with it, unless the rule is a mere reproduct of what the Constitution already says. Given this premise, the conclusion is that the legislature may impose restrictions to fundamental rights, even without explicit constitutional authorization, in order to conciliate different constitutional rights. To overcome the problems in controlling this activity, there are two theoretical propositions: the theory of the absolute essential core says that fundamental rights have irrespressible nuclear contents, protected by an insurmountable barrier, while on the other side, the theory of the relative essential core proposes that the core of the rights depends on the peculiarities of the fact situation and the fundamental prerogatives involved, establishing itself differently in each case based on balancing.
\end{abstract}

Keywords: Fundamental Rights (Civil rights). Restrictions (Limits). Factual suppor. Proportionality (balancing). Essential core

1 Doutorando em Direito pela UNIVALI. Mestre em Direito pela UNESA. Pós-graduado em Preparação à Magistratura Federal pela UNIVALI. Pós-graduado em Direito e Gestão Judiciária pela UFSC. Juiz de Direito. 


\section{INTRODUÇÃO}

O estudo se propõe à analisar a possibilidade do legislador infraconstitucional estabelecer restrições aos direitos fundamentais sem autorização constitucional expressa.

Tal discussão perpassa pela análise de diversas teorias pouco enfrentadas pela doutrina brasileira, ressalvadas recentes incursões na literatura jurídica estrangeira.

Ao examinar as teorias que permitem a resolução do questionamento proposto, é preciso ter em mente que as opções teóricas de base devem formar um quadro de interdependência com as proposições que lhe são correlatas, de modo a compor uma rede lógica que permita, sistemática e coerentemente, explicar os fenômenos jurídicos.

Por isso, na primeira subseção discorre-se sobre as teorias que dizem respeito à delimitação do conteúdo dos direitos fundamentais, ou seja, das teorias restrita e ampla do suporte fático, de modo a esclarecer quais situações podem ser tematicamente tuteladas, sob o signo de prerrogativas constitucionais. E, em um segundo momento, passa-se para a exposição das teses que discorrem sobre a contenção dos direitos fundamentais, sob as formas interna (limites imanentes) ou externa (restrições).

Depois de apresentadas tais bases teóricas, referentes à abrangência e aos limites ou restrições aos direitos fundamentais, inaugura-se o desenvolvimento das hipóteses que, conjugadas, respondem ao questionamento proposto, seguindo a trilha lógica de, primeiro, explicitar a impossibilidade de se conceber normas que sejam meramente conformadoras de direitos fundamentais e, segundo, de quais os termos em que se faculta ao parlamentar a produção de legislação complementar ou ordinária restritiva de direitos fundamentais.

Por fim, apresentam-se as conclusões obtidas, com enfoque no controle da atividade restritiva do parlamentar infraconstitucional.

\section{O suporte fático dos direitos fundamentais}

A investigação sobre a abrangência e os limites dos direitos fundamentais perpassa pelo estudo do conceito de suporte fático. Embora se trate de tema pouco explorado pelos juristas brasileiros, é alvo de intensos debates no exterior, em razão da sua importância para aferição dos contornos, da conformação, da restringibilidade e da eficácia das prerrogativas essenciais.

A primeira consideração importante sobre o conceito em tela consiste em distinguir suas duas faces interligadas, sendo a primeira representada pela previsão abstrata do ordenamento jurídico e a segunda pelo contexto concreto sobre o qual a consequência normativa incide.

Nessa linha de raciocínio, afirma-se que suporte fático em sentido abstrato é a 
construção jurídica das hipóteses de incidência da norma, mediante descrição gramatical dos fatos típicos e das suas respectivas consequências². Na seara criminal, por exemplo, é comumente chamado de tipo penal e, por via de regra, comporta duas partes bem distintas: uma incriminadora (descrição dos fatos ilícitos) e o outra sancionadora (punição prevista). No direito tributário, é geralmente intitulado de hipótese de incidência, pois contém a explicitação dos fatos jurídicos (descrição) que ensejam a cobrança de determinado tributo (consequência).

De outro lado, suporte fático em sentido concreto designa o fato jurídico, com todas as circunstâncias e detalhes relevantes, que implica a juridicização da norma ao mundo da $v$ vida $^{3}$. Trata-se da situação fática efetivamente verificada na realidade, sobre a qual se debruça o jurista para atribuição de efeitos jurídicos. Voltando aos exemplos anteriores, é o que se costuma chamar de fato típico pelos criminalistas e de fato gerador pelos tributaristas.

A segunda consideração a ser destacada acerca do tema diz respeito à variabilidade de sua definição e de sua estrutura de acordo com o respectivo ramo do direito. O suporte fático das normais penais, para retomar o exemplo, é composto pelos preceitos incriminador (descrição da conduta proibida) e sancionador (pena cominada), dos quais é possível extrair a consequência jurídica pertinente, sendo que o das normas tributárias possui composição similar, porquanto apresenta a hipótese de incidência (fato tributável) e a exação respectiva (tributo a ser lançado).

Mas, em se tratando de normas de direitos fundamentais, os dispositivos são redigidos sob a forma de declaração de prerrogativas humanísticas, de modo que "a definição do suporte fático nesses casos é menos intuitiva que nos casos dos tipos penais" ${ }^{*}$. Com efeito, ao contrário das normas criminais e tributárias acima mencionadas, não é tão simples a tarefa de aferir qual o suporte fático referente aos preceitos constitucionais que, por exemplo, estabelecem os direitos às liberdades públicas, à igualdade de tratamento e à proteção dos bens indisponíveis, em razão da sua enunciação ampla.

Na tentativa de superar tais dificuldades, Robert Alexy sugere que o suporte fático dos direitos fundamentais seja necessariamente composto por dois elementos distintos, consistentes no âmbito de proteção e na intervenção (geralmente estatal), de modo que da convergência de ambos resulta a consequência jurídica pertinente ${ }^{5}$. Isto porque a descoberta somente daquilo que é protegido pelo ordenamento jurídico, ou seja, do bem jurídico tutelado, é insuficiente para delimitar completamente o suporte fático, sendo necessário agregar também a intervenção como um segundo elemento, para que, somente então, apresente-se a

2 SILVA, Virgílio Afonso da. Direitos fundamentais: Conteúdo essencial, restrições e eficácia. São Paulo: Malheiros, 2009. p. 67.

SILVA, Virgílio Afonso da. Op. Cit. p. 68.

SILVA, Virgílio Afonso da. Op. Cit. p. 71.

5 ALEXY, Robert. Teoria dos direitos fundamentais. São Paulo: Malheiros, 2008. p. 302-307. 
consequência jurídica cabível. No mesmo sentido, Gilmar Ferreira Mendes afirma que "em relação ao âmbito de proteção de determinado direito individual, faz-se mister que se identifique não só o objeto da proteção (O que é efetivamente protegido?), mas também contra que tipo de agressão ou restrição se outorga essa proteção" ${ }^{\text {. }}$

Como exemplo, veja-se o art. 5 X, da Constituição da República Federativa do Brasil (CRFB), segundo o qual "são invioláveis a intimidade, a vida privada, a honra e a imagem das pessoas". Para definição do respectivo suporte fático não basta apenas compreender que seu âmbito de proteção é o direito à privacidade, porquanto desta constatação não decorre consequência jurídica nenhuma. É necessário agregar uma intervenção contra tal liberdade constitucional, de modo que surja a respectiva consequência jurígena, a qual consiste justamente na cessação da violação. Assim, apenas mediante a conjugação de ambos elementos (direito de defesa e intervenção indevida) é que a leitura do suporte fático permite extrair a consequência jurídica (abstenção ou término da intromissão na vida privada do titular do direito).

Esmiuçando os elementos acima mencionados, cabe referir que o âmbito de proteção aponta as posições jurídicas que são tuteladas pela norma, ou seja, é a indicação dos bens protegidos pelo direito ${ }^{7}$.

A intervenção, por sua vez, indica a atuação sobre os bens jurídicos protegidos de que trata a norma, principalmente sob as formas de embaraço, afetação ou eliminação, cuja ocorrência acarreta determinada consequência jurídica.

Complementando o tema, Virgílio Afonso da Silva propõe um "modelo alternativo" para espécie, incluindo no conceito um terceiro elemento, consistente na "ausência de fundamentação constitucional" ${ }^{\prime}$. Para o citado estudioso, a conjugação dos elementos âmbito de proteção e intervenção é ainda insuficiente para aferição da consequência jurídica, sendo imprescindível também a ausência de motivação idônea para justificar a intromissão, pois somente aí se produzirá um resultado jurídico. Nesta linha de raciocínio, a intervenção justificada em determinado âmbito protegido não acarreta consequência nenhuma. Todavia, apesar da clareza da ideia, prefere-se o modelo originalmente proposto por Robert Alexy, haja vista que a questão da fundamentação constitucional, segundo a sua teoria dos direitos fundamentais e a teoria ampla de suporte fático que adota, pertence à posterior fase de aferição da compatibilidade constitucional da restrição (esta como figura externa).

Com o modelo de suporte fático dos direitos fundamentais em exame, pode-se anotar

6 MENDES, Gilmar Ferreira. COELHO, Inocêncio Mártires. BRANCO, Paulo Augusto Gonet. Curso de direito constitucional. 3 ed. São Paulo: Saraiva, 2009. p. 329.

7 CANOTILHO, José Joaquim Gomes. Direito constitucional e teoria da constituição. 7 ed. Coimbra: Almedina, 2003. p. 1262.

8 SILVA, Virgílio Afonso da. Op. Cit. p. 74-75. 
que os direitos a ações negativas (liberdades públicas) são compostos pela proteção contra afetação (âmbito de proteção) e pelo seu embaraço (intervenção), cuja convergência faz emergir a proteção, sob as formas de abstinência do interventor ou de reparação pelos danos causados (consequência). De outra quadra, para os direitos a ações positivas (prestações públicas) concorrem a carência (âmbito de proteção) e a inércia estatal (intervenção, sob a forma de não agir ou insuficiência da atuação), cuja conjugação acarreta a obrigação de atuar, de fomentar ou de compensação de danos (consequência).

Por fim, a terceira consideração a ser feita acerca do suporte fático dos direitos fundamentais diz respeito à teoria, ampla ou restrita, utilizada para definição da sua abrangência e dos seus contornos, de modo a aferir quais ocorrências fáticas efetivamente encontram abrigo na norma.

Os prosélitos da teoria restrita do suporte fático sustentam que as normas de direitos fundamentais apresentam limites imanentes, ou seja, delas é possível extrair a proteção para determinadas situações incluídas em seu conteúdo normativo, enquanto outras hipóteses ultrapassam seus contornos e, então, carecem de tutela jurídica. Para doutrina, "a característica principal das teorias que pressupõem um suporte fático restrito para as normas de direito fundamental é a não-garantia a algumas ações, estados ou posições que poderiam ser, em abstrato, subsumidas no âmbito de proteção dessas normas" ". Como consequência lógica, a teoria sob foco desloca a discussão sobre abrangência e eficácia dos direitos fundamentais para dentro do âmbito da norma, de modo que a aferição de quais situações devem ser abrangidas e de quais merecem ser excluídas é efetuada pelo emprego de critérios delimitativos de seu conteúdo e dos respectivos limites. Sob este prisma de análise, não se concebem direitos e restrições que lhe são externas, mas sim em extensão da validade de direitos, os quais são inaplicáveis além de seus limites internos.

A teoria do alcance material de Friedrich Müller é um exemplo de suporte fático restrito, porquanto defende que os direitos fundamentais não podem ser ilimitados e que, consequentemente, a interpretação e a aplicação das normas que os estabelecem pressupõem a definição exata de seu conteúdo e de seus limites ${ }^{10}$. Para o mencionado jurista, "a tarefa principal da dogmática jurídica dos direitos fundamentais é a precisa delimitação da amplitude fática de cada um desses direitos", sendo que "definir o conteúdo daquilo que é protegido por cada direito fundamental é, portanto, o mesmo que definir os seus limites"11. Sem embargo, ao se estabelecer as hipóteses que estão contidas no âmbito normativo, automaticamente se fixa o que não está abarcado pela proteção jurídica.

9 SILVA, Virgílio Afonso da. Op. Cit. p. 79-80.

10 ALEXY, Robert. Op. Cit. p. 309-311.

11 SILVA, Virgílio Afonso da. Op. Cit. p. 86. 
A teoria de Friedrich Müller apresenta dois critérios decisivos para o estabelecimento dos limites dos direitos fundamentais, consistentes em especificidade e intercambialidade. Em uma breve síntese, para os fins desta exemplificação, pode-se enunciar especificidade como o parâmetro para o estabelecimento do âmbito material da norma, o qual é integrado somente pelas modalidades com conexão direta e específica ao direito fundamental respectivo ${ }^{12}$. A conformação de um determinado direito fundamental depende, então, da inclusão em sua esfera de proteção apenas daqueles exercícios que lhe são especificamente conexos, muito embora tal relação dependa de construção dogmática pela doutrina e pela jurisprudência. Por outro lado, a intercambialidade indica que os aspectos suscetíveis de substituição por outros, sem perda significativa para o exercício de um direito fundamental específico, não integram o respectivo conteúdo normativo ${ }^{13}$. Portanto, segundo a proposta teórica em exame, é possível excluir da extensão normativa do direito fundamental aqueles elementos que não lhe são estruturalmente variáveis, ainda que lhe sejam casualmente associados.

A construção restrita do suporte fático, ainda que nos moldes refinados por Friedrich Müller, apresenta debilidades, mormente em razão da dificuldade em se estabelecer com precisão qual a efetiva abrangência dos direitos fundamentais. Aponta-se que "a principal dificuldade que qualquer teoria que pressuponha um suporte fático restrito para os direitos fundamentais tem que enfrentar é o método de definição desse suporte”, ou seja, estabelecer "com base em quais critérios condutas que, prima facie, poderiam ser consideradas como garantidas por algum direito poderão ser excluídas, em abstrato e definitivo, dessa garantia"14. Os critérios apresentados pelos adeptos de tal tese não permitem um grau satisfatório de segurança na definição em abstrato do conteúdo e dos limites dos direitos fundamentais, mostrando-se meramente intuitivos, porque não apontam com clareza as linhas divisórias entre aquilo que é tutelado e o que não é, deixando uma área de penumbra cinzenta sem definição. Isto se complica ainda mais quando estão em contradição dois direitos fundamentais, circunstância em que o intérprete tem que estabelecer os exatos contornos divisórios entre ambos para o caso concreto e, também, para outros similares que possam ocorrer no futuro, já que a teoria pressupõe que os seus limites são imanentes, extraíveis $a$ priori da norma.

A teoria também apenas aparentemente esvazia a necessidade de ponderação entre direitos constitucionais em oposição. Isto porque, em verdade, o que ocorre é simplesmente um deslocamento do sopesamento, outrora situado no debate sobre um direito e a sua restrição, para o âmbito interno da norma, no nível da definição dos exatos limites dos direitos

12 ALEXY, Robert. Op. Cit. p. 311-312.

13 SILVA, Virgílio Afonso da. Op. Cit. p. 88.

14 SILVA, Virgílio Afonso da. Op. Cit. p. 97. 
fundamentais. E tal deslocamento é desaconselhável, porque implica anacronismo e conservadorismo alheios à plasticidade das relações sociais e econômicas, ao tornar imprescindível a fixação de um específico limite para o direito que, posteriormente, pode apresentar-se severamente restritivo de uma prerrogativa humana, bastando que o caso concreto tenha circunstâncias diferentes. Ora, da teoria restrita decorre "a impossibilidade de atualização do âmbito de proteção dos direitos fundamentais a uma realidade cambiante", na exata medida em que fixa limites para os direitos fundamentais válidos para o futuro, de sorte a fechar as portas para novas conformações, ainda que o desenvolvimento tecnológico ou social as reclame ${ }^{15}$.

A teoria ampla do suporte fático, diversamente da anterior, propugna uma amplitude aberta da norma, para que abranja todas as situações que isoladamente tenham conexão com seu espectro temático. Outrossim, "uma teoria ampla do suporte fático é uma teoria que inclui no âmbito de proteção de cada princípio de direito fundamental tudo aquilo que milite em favor de sua proteção" ". O suporte fático amplo abarca "toda ação, estado ou posição jurídica que tenha alguma característica que, isoladamente considerada, faça parte do 'âmbito temático' de um determinado direito fundamental [...], independentemente de outras variáveis" $" 17$.

Como já mencionado, o suporte fático dos direitos fundamentais é composto pelo âmbito de proteção e pela intervenção, sendo que, para teoria ampla, ambos devem ser concebidos da forma mais abrangente possível. Outrossim, qualquer aspecto conexo com determinado direito fundamental deve ser considerado protegido por ele, enquanto qualquer afetação, eliminação ou embaraço deve ser tido como uma interferência na área protegida ${ }^{18}$.

$\mathrm{O}$ referido alargamento do suporte fático, inerente à teoria ampla, rejeita a existência de limites imanentes aos direitos fundamentais e, consequentemente, acarreta uma maior tensão entre eles, justamente porque o espectro de incidência de cada um deles se espraia sobre uma maior variedade de situações concretas. Neste cenário, a delimitação da proteção jurídica deve ser efetuada para além da teoria da norma, na fase de interpretação e aplicação, por intermédio das meta-regras que tratam da contradição entre normas. Logo, enquanto na teoria restrita a discussão reside na fixação do conteúdo de cada direito (qual o limite próprio e inerente a cada direito, para aferição daquele incidente in casu), na teoria ampla, por suas especificidades, o debate sobre a solução jurídica adequada desenvolve-se mediante a ponderação entre direitos distintos e sua incidência nos casos concretos (qual dos direitos,

15 SILVA, Virgílio Afonso da. Op. Cit. p. 95-97.

16 ALEXY, Robert. Op. Cit. p. 322.

17 SILVA, Virgílio Afonso da. Op. Cit. p. 109.

18 ALEXY, Robert. Op. Cit. p. 322-323. 
ambos abrangentes do caso, deve preponderar na espécie).

Como se pode perceber, sob a ótica analítica, a teoria do suporte fático amplo não encontra as mesmas dificuldades apresentadas pela restrita, principalmente porque não paga o alto preço de justificação necessário para definição de seu âmbito de proteção e de sua intervenção, na medida em que simplesmente os considera da forma mais abrangente possível. E, além disto, tem a vantagem de reservar o debate argumentativo sobre a prevalência do direito somente para a fase de interpretação e aplicação em concreto, cujo controle não depende de conceitos meramente intuitivos e apriorísticos (como os de especificidade e intercambialidade), mas sim de critérios meta-jurídicos bem definidos e de acordo com circunstâncias concretas efetivas, a exemplo da técnica de ponderação de interesses.

\section{Limites ou restrições de direitos fundamentais}

As restrições aos direitos fundamentais são compreendidas de acordo com as teorias interna ou externa, as quais estão intimamente interligadas com a opção entre as teses dos suportes fáticos restrito ou amplo acima explicitadas.

A teoria interna das limitações aos direitos fundamentais (Innentheorie) apregoa que é possível fixar a extensão e os limites dos direitos mediante uma análise interna, sem influência de aspectos exteriores. Sob esta ótica, os direitos terminam onde e quando os abusos começam. Outrossim, "é a partir do enfoque da teoria interna - e daí o seu nome -, que o processo de definição dos limites de cada direito é algo interno a ele. É sobretudo nessa perspectiva que se pode falar em limites imanentes"19. Por isto se afirma que, na teoria restrita, "a ideia de restrição (Schranke) é substituída pela de limite (Grenze)",20.

Como se pode perceber, a teoria interna das restrições está intimamente relacionada com a tese do suporte fático restrito dos direitos fundamentais, haja vista ambas sustentarem que as prerrogativas humanas são compreendidas em si mesmas, mediante o estabelecimento de seu conteúdo e de seus contornos, independentemente de confrontação com elementos externos. É nesta senda que se pode falar em limites imanentes ao próprio direito, mas não se admite a suscitação de restrições, pois estas são fatores exteriores e desligados do processo de definição do espectro normativo.

A teoria externa das restrições aos direitos fundamentais (Aussentheorie), diferentemente da anterior, está fulcrada na ideia de que os direitos são amplos e não apresentam limites inerentes, porém, fatores externos lhe impõem restrições. Destarte, "ao

19 SILVA, Virgílio Afonso da. Op. Cit. p. 128.

20 MENDES, Gilmar Ferreira. COELHO, Inocêncio Mártires. BRANCO, Paulo Augusto Gonet.Op. Cit. p. 334. 
contrário da teoria interna, que pressupõe a existência de apenas um objeto, o direito e seus limites (imanentes), a teoria externa divide esse objeto em dois: há, em primeiro lugar, o direito em si, e, destacadas dele, as suas restrições"21.

Nessa trilha lógica, a teoria externa das restrições vai ao encontro da tese do suporte fático amplo, pois ambas pressupõem que cada prerrogativa jurídica é estabelecida de forma abrangente, contudo, a sua coexistência com direitos iguais ou específicos de outros indivíduos ou da coletividade lhe imprime restrições, com as quais deve ser harmonizada ${ }^{22}$. E tal conciliação entre distintos direitos é efetuada mediante a ponderação deles em cada caso concreto, de modo a verificar quais as respectivas extensões e restrições na espécie, observando-se a precedência condicionada em futuras contradições com circunstâncias similares (dever de coerência).

Das considerações acima expostas, é possível se extrair a conclusão de que a adoção de um suporte fático restrito enseja preferencialmente a opção pela teoria interna, pois ambas refletem na existência de limites imanentes (internos) aos direitos fundamentais. De outro lado, a escolha do suporte fático amplo implica predileção pela tese externa, pois pressupõe o estabelecimento de direitos abrangentes com restrições vindas da ponderação com outras prerrogativas. De fato, "quando se parte de uma teoria interna, que é aquela que sustenta que o direito e seus limites são algo uno - ou seja, que os limites são imanentes ao próprio direito -, isso exclui que outros fatores externos, baseados, por exemplo, na ideia de sopesamento entre princípios, imponham qualquer restrição extra" 23 . Isto força a ilação de que "a figura dos limites imanentes e o conceito de sopesamento são mutuamente exclusivos"24.

Não se olvida, contudo, a existência de pensamentos jurídicos no sentido de separar os binômios interligados na forma acima mencionada (restrita/interna e ampla/externa), optando pelas mixagens restrita/externa ou ampla/interna, com adaptações necessárias para conjugar tais proposições teóricas, aparentemente inconciliáveis na sua formulação ${ }^{25}$. Outros autores, ainda, propõem conceitos diferentes para os elementos das teorias até aqui desenvolvidas, de modo a compatibilizar proposições aparentemente antagônicas, a exemplo da definição de limites imanentes como "resultado de uma ponderação de princípios", deduzida por Joaquim José Gomes Canotilho ${ }^{26}$.

Todavia, este trabalho adota a terminologia acima alinhavada, pelos motivos antes delineados, e, desta forma, aponta para uma prevalência da combinação teorias ampla do

SILVA, Virgílio Afonso da. Op. Cit. p. 138.

ALEXY, Robert. Op. Cit. p. 277.

SILVA, Virgílio Afonso da. Op. Cit. p. 128.

SILVA, Virgílio Afonso da. Op. Cit. p. 133.

SILVA, Virgílio Afonso da. Op. Cit. p. 158-168.

CANOTILHO, José Joaquim Gomes. Op. Cit. p. 1282. 
suporte fático e externa das restrições.

\section{Conformação e/ou restrição de direitos fundamentais}

A defesa do binômio representado pelas teorias ampla do suporte fático e externa das restrições abre espaço para discussão em torno da possibilidade do legislador infraconstitucional estabelecer preceitos normativos que apenas conformem ou regulem o exercício de determinados direitos fundamentais, sem impor-lhes restrições em qualquer nível ou dimensão. De fato, os doutrinadores divergem quanto à possibilidade do parlamentar infraconstitucional, antevendo eventuais contradições de prerrogativas fundamentais, efetuar ponderações prévias aos conflitos concretos sob a forma de preceitos legais, estabelecendo certos critérios, condições ou formas para o exercício dos direitos fundamentais, a pretexto de otimizar ou harmonizar interesses colidentes, sem criar quaisquer restrições.

Joaquim José Gomes Canotilho entende que é plausível a existência de normas meramente regulamentadoras de direitos fundamentais, cuja interpretação e aplicação não revelam nenhuma restrição ao direito fundamental que visam conformar. Para ele, "muitas normas legais pretendem completar, complementar, densificar, concretizar, o conteúdo fragmentário, vago, aberto, abstracto ou incompleto, dos preceitos constitucionais garantidores de direitos fundamentais" ${ }^{27}$. Como exemplos de tais normas, menciona aquelas que regulam o matrimônio ou a associação partidária, mormente porque são pressuposto para o exercício dos direitos fundamentais correlatos, em razão de estabelecerem posições jurídicas de competências.

Robert Alexy, por outro lado, defende um conceito restrito para as normas meramente configuradoras, pois entende haver uma restrição de direito fundamental "sempre que um sopesamento orientado pela máxima da proporcionalidade seja necessário (caso real de direitos fundamentais) ou simplesmente possível (caso potencial) ${ }^{\text {28 }}$. Para ele, apenas tal concepção "é compatível com as exigências de racionalidade na fundamentação dos casos envolvendo direitos fundamentais" ${ }^{29}$. Ressalta ainda que mesmo as normas fixadoras de posições jurídicas de competências, a exemplo daquelas que dispõem sobre o direito fundamental à propriedade, podem eventualmente representar restrições, desde que impliquem proibições à liberdade em geral ou, ainda, revoguem configurações mais amplas outrora existentes ${ }^{30}$.

Entre os doutrinadores brasileiros, Gilmar Ferreira Mendes sufraga a tese de que o legislador tem o dever de regulamentar e conformar os direitos fundamentais que dependem

CANOTILHO, José Joaquim Gomes. Op. Cit. p. 1263.

28 ALEXY, Robert. Op. Cit. p. 399.

29 ALEXY, Robert. Op. Cit. p. 340.

30 ALEXY, Robert. Op. Cit. p. 336-337. 
de sua interferência para se concretizarem, embora esteja constitucionalmente limitado ao estabelecer restrições ${ }^{31}$.

Suzana de Toledo Barros tem posicionamento similar, no sentido de que a atividade legislativa é necessária para precisar a forma e o conteúdo dos direitos fundamentais, embora admita que "as fronteiras entre a restrição de direitos e simples conformação da norma constitucional só podem ser demarcadas por processo de interpretação, diante, pois, de uma situação concreta",32.

Virgílio Afonso da Silva, porém, contraria os juristas antes mencionados ao sustentar ser inconcebível uma atividade legiferante meramente conformadora ou regulamentadora, mormente em face da teoria do suporte fático amplo dos direitos fundamentais, na medida em que qualquer cláusula normativa estabelecida acabará inevitavelmente implicando uma restrição ao right respectivo, ainda que em grau diminuto ${ }^{33}$. Segundo ele, "é perfeitamente possível que, com base em medidas aparentemente inofensivas e meramente regulamentadores o exercício de um direito fundamental possa ser restringido de forma contundente. O que aparenta ser uma regulamentação é, na verdade, restrição" ${ }^{\text {"34. }}$.

Sem embargo, os preceitos infraconstitucionais que tratam de proibições, mandamentos ou permissões claramente estabelecem alguma espécie de restrição ao conteúdo das prerrogativas constitucionais. Mesmo os preceitos que tratam de posições jurídicas de competência implicam alguma restrição, ainda que de baixa amplitude, ao direito fundamental respectivo, pois fixam determinados modos, formas, prazos, locais, tempo, processos, condições, métodos ou intensidades para o seu exercício, em detrimento de outras vias ou alternativas que poderiam estar disponíveis ao seu titular. Ainda que se tratem de normas que visam concretizar os direitos plasmados na Constituição, há alguma restrição implícita, pois tais dispositivos trazem elementos de efetividade sob determinada estrutura ou mediante certo procedimento, desprezando outras possibilidades de realização no mundo da vida. Assim, "a distinção entre restrição e regulação é mitigada, e toda regulação deve ser considerada, ao mesmo tempo, uma restrição, visto que regular o exercício de um direito implica excluir desse exercício aquilo que a regulação deixar de fora" ${ }^{35}$.

Justamente por isso, é impensável uma norma jurídica que disponha sobre um direito fundamental sem implicar restrições ou limites, salvo um texto que se apresente como uma

31 MENDES, Gilmar Ferreira. COELHO, Inocêncio Mártires. BRANCO, Paulo Augusto Gonet. Op. Cit. p. 332-333.

32 BARROS, Suzana de Toledo. O princípio da proporcionalidade e o controle de constitucionalidade das leis restritivas de direitos. 2 ed. Brasília: Brasília Jurídica, 2000. p. 154.

33 SILVA, Virgílio Afonso da. Op. Cit. p. 40-41 e 100-108.

34 SILVA, Virgílio Afonso da. Op. Cit. p. 102.

35 SILVA, Virgílio Afonso da. Op. Cit. p. 42. 
reprodução idêntica ou expansiva de algo já disposto na Constituição, sem qualquer conformação efetiva. É inclusive desnecessária qualquer norma infraconstitucional disciplinadora de direitos fundamentais que não enfrente eventuais colisões ou fixe certos critérios, limites ou condições ao seu exercício.

Exemplificativamente, o art. $1^{\circ}, \S 1^{\circ}$, da Lei $12.016 / 2009$ aparentemente apenas conforma o mandado de segurança previsto no art. 5, LXIX, da Constituição da República Federativa do Brasil (CRFB), ao supostamente expandir a amplitude do conceito de autoridade pública, de modo a conferir efetividade processual a tal remédio protetivo. $\mathrm{O}$ referido preceito diz que "equiparam-se às autoridades, para os efeitos desta Lei, os representantes ou órgãos de partidos políticos e os administradores de entidades autárquicas, bem como os dirigentes de pessoas jurídicas ou as pessoas naturais no exercício de atribuições do poder público, somente no que disser respeito a essas atribuições”. À primeira vista, tal preceito não apresenta qualquer limitação ao emprego do mandamus e, até pelo contrário, expande as pessoas que podem figurar no polo passivo da impetração. Todavia, uma leitura mais atenta revela que, primeiro, há uma restrição à prerrogativa constitucional quando prevê que só atos vinculados às suas atribuições podem ser questionados (“[...] somente no que disser respeito a essas atribuições”), reduzindo a área de efeito sobre diversas condutas que possam ser violadoras no caso concreto. Em segundo lugar, ao se aparentemente inflacionar o conceito de autoridades públicas, reduz-se a margem de manobra quanto à interpretação de tal conceito pelo Poder Judiciário, porque tal definição é dada previamente pelo legislador. E, terceiro, embora se possa entender que a equiparação de "representantes ou órgãos de partidos políticos e os administradores de entidades autárquicas, bem como os dirigentes de pessoas jurídicas ou as pessoas naturais no exercício de atribuições do poder público" esteja alargando o conceito de autoridade pública e, assim, explicitando (e não restringindo) o direito fundamental em tela, por outro lado, há de se considerar que tal ampliação enseja restrições a outros direitos fundamentais, justamente das pessoas que podem figurar na outra ponta da postulação, que agora podem ter sua conduta questionada pela via mandamental, embora outra interpretação pudesse, antes da edição do dispositivo legal, franquear conclusão diferente.

Em síntese, qualquer dispositivo supostamente regulamentador representa alguma restrição, ainda que em intensidade ínfima, ao direito fundamental respectivo ou a outros que com ele possam colidir, salvo se o preceito for mera reprodução do conteúdo constitucional das prerrogativas envolvidas sob outra roupagem, hipótese em que, na verdade, não há qualquer conformação. Consequentemente, regulamentação implica algum grau de restrição, de modo a invalidar a classificação das normas infraconstitucionais entre meramente 
conformadoras ou restritivas de direitos fundamentais. É da essência dos preceitos legais importar alterações no suporte fático dos direitos e, ao fazê-lo, certamente impõem-lhe determinadas restrições. Até porque é flagrantemente desnecessário um preceito legal que em nada modifique o suporte fático do direito sobre o qual dispõe, pois fatalmente será mera reprodução de conteúdos já plasmados.

Dessa conclusão (inexistência de normas infraconstitucionais não-restritivas de direitos fundamentais) decorre o questionamento objeto deste artigo, atinente à possibilidade do legislador estabelecer restrições a direitos fundamentais sem autorização constitucional expressa.

\section{Restrições infraconstitucionais aos direitos fundamentais}

Há importante debate doutrinário e jurisprudencial sobre a viabilidade do congressista efetuar ponderações entre prerrogativas colidentes com o objetivo de estabelecer restrições sem que haja autorização constitucional expressa para tanto.

Partindo-se da premissa exposta no item anterior (inexistência de normas infraconstitucionais não-restritivas de direitos fundamentais), a resposta à indagação ora em tela só pode ser positiva, no sentido de que a produção legislativa pode impor contornos aos direitos fundamentais, ainda que sem autorização constitucional expressa para tanto, estabelecendo as chamadas restrições implícitas. Ora, se toda norma que discorre sobre direitos fundamentais envolve contenções em algum grau, negar ao congressista o poder de estabelecer restrições às faculdades essenciais quando não houver previsão constitucional implica, consequentemente, vedar-lhe qualquer possibilidade de dispor acerca dos direitos fundamentais individuais ou coletivos, de forma a limitar sobremaneira a sua função estatal precípua.

Nessa linha de raciocínio, o parlamentar pode constituir novas restrições além daquelas já eventualmente previstas diretamente (restrições diretas) ou facultadas (reserva legal para imposições restritivas) no texto fundamental, na qualidade de poder estatal constituído, desde que tal atividade criativa esteja lastrada em outros preceitos constitucionais. Notadamente, a submissão do legislador à Constituição não pode ser tão forte ao ponto de lhe proibir a produção de preceitos legais disciplinadores (e, portanto, restritivos) de direitos fundamentais, sob pena de contradizer a própria previsão constitucional do processo legiferante, pois este tornaria-se desnecessário.

Nesse diapasão, importa transcrever o art. $4^{\circ}$ da Declaração dos Direitos do Homem e do Cidadão, de 26.08.1789, segundo o qual "a liberdade consiste em poder fazer tudo aquilo que não prejudique outrem: assim, o exercício dos direitos naturais de cada homem não tem 
por limites senão os que asseguram aos outros membros da sociedade o gozo dos mesmos direitos. Estes limites apenas podem ser determinados por lei” (grifou-se).

Porém, a produção legislativa infraconstitucional deve observar os parâmetros estabelecidos no sistema constitucional, ou seja, a produção normativa é balizada pela ponderação entre os interesses fundamentais colidentes, consoante critérios de proporcionalidade.

Exemplificando a ilação acima exposta em face da ordem jurídica brasileira, verificase que não há autorização constitucional expressa para que o legislador estabeleça as várias restrições ao direito fundamental de liberdade (art. $5^{\circ}$, caput, da CRFB) contidas no Código Penal. Mesmo assim, não se vislumbra inconstitucionalidade no art. 121 do CP, que proíbe o assassinato, sob pena privativa de liberdade, com o intuito de preservar o direito fundamental à vida (também previsto no art. $5^{\circ}$, caput, da CRFB), de modo a demonstrar que há um reconhecimento implícito para o poder legislativo restritivo de prerrogativas essenciais. Da mesma forma, o direito constitucional à livre propagação de ideias políticas não é contraposto por cláusulas de limitabilidade (art. $5^{\circ}, \mathrm{IV}$, da CRFB), entretanto, a proibição da propaganda eleitoral no dia do sufrágio ("boca de urna”), prevista no art. 39 , § 5 , I a III, da Lei 9.504/1997, apresenta-se compatível com o texto fundamental, porquanto fundada no sopesamento com o direito ao voto livre (art. 14 da CRFB). O ordenamento jurídico brasileiro é composto por diversos exemplos similares, de modo a justificar a possibilidade da atuação constitutiva de restrições pelos parlamentares.

Tal conclusão é corroborada por Robert Alexy, para quem “o legislador tem, portanto, uma competência constitutiva para imposição de restrições", entretanto, ressalva que "é inadmissível uma restrição a um princípio de direito fundamental que extrapole aquilo que é admissível em face do peso dos princípios colidentes"36.

Na mesma senda, Konrad Hesse assevera que "só se admitem restrições quando se revestem do interesse do bem comum, isto é, quando se podem justificar com considerações objetivas e razoáveis do bem comum e se compadecem também do princípio da proporcionalidade (em sentido amplo), ${ }^{, 37}$.

Também parcela da doutrina brasileira entende que, "em matéria de direitos fundamentais, o primeiro grau de concretização jurídica já é dado pelas normas superiores"38. E que, justamente por isto, "a configuração de uma colisão poderia legitimar, assim, o estabelecimento de restrição a um direito não submetido a reserva legal expressa", porquanto,

36 ALEXY, Robert. Op. Cit. p. 294-295.

37 HESSE, Konrad. Temas fundamentais de direito constitucional. São Paulo: Saraiva, 2009. p. 65.

38 BARROS, Suzana de Toledo. Op. Cit. p. 153. 
“nesses casos, o legislador pode justificar a sua intervenção com fundamento nos direitos de terceiros ou de outros princípios de hierarquia constitucional" ${ }^{\prime 39}$.

Para alguns autores, inclusive, a produção de regras restritivas de direitos fundamentais, mediante a ponderação de princípios constitucionais colidentes segundo a meta-regra da proporcionalidade é considerada "uma tarefa central da legislação ordinária" 40 .

Diante desse quadro de argumentos, a resposta ao questionamento em voga aponta pela possibilidade do legislador efetuar a ponderação dos interesses envolvidos, segundo os critérios políticos de conveniência e oportunidade inerentes à sua atividade, com o objetivo de produzir legislação complementar ou ordinária que reduza a margem de atuação do intérprete e aplicador do direito no ponto, desde que balizado por outros princípios constitucionais, sopesados segundo critérios de proporcionalidade.

\section{Classificação das normas restritivas de direitos fundamentais}

Considerando as premissas antes fixadas, pode-se montar uma classificação das normas restritivas de direitos constitucionais, separando-as em diretamente constitucionais, indiretamente constitucionais e implícitas ${ }^{41}$.

As restrições diretamente constitucionais, também chamadas de restrições constitucionais imediatas, são aquelas estabelecidas pelo próprio texto fundamental, sob a forma de cláusulas de exceção expressas e diretamente relacionadas com o direito fundamental respectivo, redigidas no mesmo dispositivo ou em preceitos complementares. Esta modalidade ocorre "toda vez que a Constituição, ao conceder um direito fundamental, diretamente, consigna restrições ao seu exercício ou efetua delimitações quanto a sua abrangência normativa", 42 .

As restrições indiretamente constitucionais, ou restrições mediatas expressas, são aquelas expressamente autorizadas pela Constituição, sob a forma de reservas legais restritivas expressas, nas formas simples ou qualificada. A intervenção possui natureza simples quando o texto fundamental expressamente faculta ao legislador a possibilidade de restringir direitos mediante edição de preceitos de ordem hierárquica inferior (leis complementares ou ordinárias), sem estabelecer quais parâmetros a serem seguidos. De outro

39 MENDES, Gilmar Ferreira. COELHO, Inocêncio Mártires. BRANCO, Paulo Augusto Gonet. Op. Cit. p. 347-348.

40 SILVA, Virgílio Afonso da. Op. Cit. p. 179.

41 ZANON JUNIOR, Orlando Luiz. Máxima da proporcionalidade aplicada: a quebra do sigilo bancário pelo Fisco e o direito fundamental à vida privada. Florianópolis: Momento Atual, 2004. p. 91-94.

42 SCHÄFER, Jairo Gilberto. Direitos fundamentais: proteção e restrições. Porto Alegre: Livraria do Advogado, 2001. p. 92-93. 
lado, a restrição é qualificada "quando a Constituição não se limita a exigir que eventual restrição ao âmbito de proteção de determinado direito seja prevista em lei, estabelecendo, também, as condições especiais, os fins a serem perseguidos ou os meios a serem utilizados" $"$.

E, por fim, as restrições constitucionais implícitas ou não expressamente autorizadas são aquelas estabelecidas pelo legislador infraconstitucional sem previsão constitucional expressa, com o objetivo de harmonizar os diversos interesses colidentes previstos no sistema constitucional. Para José Joaquim Gomes Canotilho, "o seu reconhecimento é muito problemático, mas a sua admissibilidade é justificada, no contexto sistemático da constituição, em nome da salvaguarda de outros direitos ou bens" ${ }^{\natural 4}$.

De acordo com tal classificação, a atividade legiferante pode estabelecer restrições a direitos fundamentais, desde que haja reserva constitucional simples ou qualificada neste sentido ou quando, apesar da ausência de autorização expressa, a harmonização sistêmica dos interesses fundamentais recomendar tal iniciativa.

\section{Limites à atividade restritiva do legislador infraconstitucional}

Os poderes legislativos para o estabelecimento de restrições aos direitos fundamentais não são ilimitados, porquanto não podem chegar ao ponto de excluí-los do ordenamento jurídico ou de negar o seu conteúdo essencial.

Quanto à impossibilidade de se excluir princípios de direito fundamental do texto constitucional, isto é decorrência lógica da estrutura sistêmica do ordenamento jurídico, haja vista que, mesmo quando não preponderem em determinado caso concreto, permanecem no sistema para balizar futuras ponderações, decorrentes de contradições em circunstâncias distintas ${ }^{45}$.

Porém, no concernente aos limites legiferantes decorrentes da cláusula de proteção do conteúdo essencial, o debate doutrinário apresenta maiores dificuldades, mormente quanto à problemática definição da efetiva extensão de tal núcleo jurídico. De fato, "a determinação da essência de um direito não é tarefa fácil, sobretudo quando ela se coloca perante os juízos de balanceamento de bens e direitos em caso de conflito" 46 . Para superação de tais problemas, foram desenvolvidas duas proposições teóricas predominantes, consistentes nas teorias absoluta e relativa.

Segundo a teoria absoluta do conteúdo essencial (absolute Theorie), cada direito

43 MENDES, Gilmar Ferreira. COELHO, Inocêncio Mártires. BRANCO, Paulo Augusto Gonet. Op. Cit. p. 343.

44 CANOTILHO, José Joaquim Gomes. Op. Cit. p. 1277.

45 ALEXY, Robert. Op. Cit. p. 135-139.

46 CANOTILHO, José Joaquim Gomes. Op. Cit. p. 261-262. 
fundamental possui uma parcela nuclear indelével e irrestringível, porquanto protegida por uma barreira intransponível. Tal proposição teórica apresenta duas vertentes, a estática e a dinâmica. Para os prosélitos da tese absoluta e estática, o núcleo essencial é, simultaneamente, intangível e imutável, isto é, não sofre mutações ao longo do tempo, apesar dos avanços sociais e tecnológicos. Já a teoria absoluta e dinâmica enfoca a possibilidade do conteúdo essencial sofrer modificações com o decurso da história, embora não admita relativações em face de contingências ${ }^{47}$.

Como se pode perceber, a teoria absoluta, em seus aspectos estático ou dinâmico, reforça a tese da inviolabilidade de determinada partícula dos direitos fundamentais, entretanto, pouco ou nada contribui para esmiuçar qual seria tal conteúdo mínimo intangível, podendo "converter-se, em muitos casos, numa fórmula vazia, dada a dificuldade ou até mesmo impossibilidade de se demonstrar ou caracterizar in abstracto a existência desse mínimo essencial" 48 . Sem embargo, "o grande desafio de qualquer teoria absoluta sobre o conteúdo essencial dos direitos fundamentais é a definição do que pertence a esse conteúdo e do que dele deve ser excluído" 49 . Logo, justamente por não permitir a identificação, sequer aproximada, de qual o objeto que pretende tutelar, o conteúdo essencial concebido sob os auspícios da teoria absoluta apresenta-se como uma garantia inócua e dispensável, salvo como argumento meramente retórico.

Acrescenta-se que o estabelecimento de prerrogativas fundamentais inderrogáveis em quaisquer situações pode criar impasses insuperáveis, mormente quando direitos essenciais pressuponham a ultrapassagem da barreira intangível proposta pela teoria absoluta em determinados casos concretos. De fato, a concepção de direitos absolutos, ainda que só quanto à partícula ínfima de seu conteúdo, pode gerar prejuízos incontornáveis para harmonização das prerrogativas previstas no sistema constitucional.

Exemplificativamente, as ordens judiciais de quebra do sigilo bancário implicam inegável supressão do direito fundamental à privacidade em determinado caso concreto, haja vista que fulminado o segredo em prol de alguém. Embora tal comando possa ter o objetivo de tutelar interesses constitucionais mais relevantes (o direito de um menor à pensão alimentícia, por exemplo), é inconcebível sob o prisma da teoria absoluta. Da mesma forma, a pessoa que cumpre a pena de prisão em regime fechado, em razão do cometimento de crime grave, tem seu direito fundamental de liberdade totalmente aniquilado durante certo lapso de tempo, de modo que tal medida também é inadmissível para proposição teórica em tela.

47 SILVA, Virgílio Afonso da. Op. Cit. p. 187-189.

48 MENDES, Gilmar Ferreira. COELHO, Inocêncio Mártires. BRANCO, Paulo Augusto Gonet. Op. Cit. p. 351.

49 SILVA, Virgílio Afonso da. Op. Cit. p. 187. 
A teoria relativa do conteúdo essencial (relative Theorie), por sua vez, propõe que o núcleo central dos direitos depende das peculiaridades da situação fática e das prerrogativas fundamentais envolvidas, firmando-se diferentemente em cada caso concreto, mediante sopesamento fundamentado. Daí decorre que "as teorias que pressupõem um conteúdo essencial relativo identificam esse núcleo com o produto da aplicação da regra da proporcionalidade" ${ }^{, 50}$.

Tal formulação teórica estabelece íntima relação entre o conceito de conteúdo essencial e a proporcionalidade, na medida em que leva à conclusão de que os sopesamentos corretamente efetuados não ofendem o núcleo das prerrogativas essenciais. Caso contrário, se não fosse firmada tal relação entre núcleo essencial e proporcionalidade, consoante proposto pela teoria relativa, "seria necessário aceitar que restrições a direitos fundamentais, ainda que proporcionais, pudessem eventualmente afetar seu conteúdo essencial" $"$.

Logo, a teoria relativa é preferível justamente por permitir a harmonização de direitos fundamentais de acordo com as peculiaridades envolvidas em cada caso concreto, sem necessidade de se socorrer a formulações meramente intuitivas ou até jusnaturalistas quanto à delimitação de parcelas intangíveis de direitos.

Reiterando-se os exemplos antes expostos, a teoria relativa admite a possibilidade de ordem judicial de quebra do sigilo bancário ou, ainda, a prisão de pessoa pela prática de crime grave, desde que em prol da proteção de interesses coletivos mais relevantes no caso concreto, de acordo com ponderação balizada pela proporcionalidade.

A teoria relativa pressupõe que o conteúdo essencial não é aferido de forma isolada para cada direito, mas, pelo contrário, somente revela-se em cada hipótese após o escorreito sopesamento das condições fáticas e jurídicas existentes, consoante parâmetros de adequação, necessidade e proporcionalidade em sentido estrito. Deste modo, não se estabelece uma "dupla garantia dos direitos fundamentais", consistentes em "proporcionalidade e conteúdo essencial" 52 , porquanto ambas se reduzem na ponderação dos interesses constitucionais envolvidos na hipótese.

Nessa linha lógica, os limites para atividade conformadora e restritiva de direitos fundamentais pelo legislador infraconstitucional residem exatamente na ponderação dos interesses envolvidos na temática objeto da legislação complementar ou ordinária a ser produzida, observadas as possibilidades fáticas e jurídicas existentes, de acordo com a metaregra da proporcionalidade.

Por outro lado, acaso a norma restritiva seja questionada judicialmente, deve-se

50 SILVA, Virgílio Afonso da. Op. Cit. p. 198.

51 SILVA, Virgílio Afonso da. Op. Cit. p. 198.

52 SILVA, Virgílio Afonso da. Op. Cit. p. 200. 
privilegiar a opção política de conveniência e oportunidade efetuada pelo parlamentar democraticamente eleito ${ }^{53}$, ressalvada a hipótese da inconstitucionalidade emergir de um sopesamento cujos argumentos de base sejam insustentáveis, em face de determinado sistema normativo.

Notadamente, apesar do princípio formal da separação dos poderes, os preceitos contramajoritários firmados na Constituição da República vinculam também o legislador, o qual é controlado pela jurisdição na sua atividade conformadora (restritiva) de direitos fundamentais (judicial review), sob pena de ruptura no sistema de pesos e contrapesos. Muito embora o estudo da separação dos poderes não seja objeto desta investigação, importa consignar o entendimento de que "sem a instituição da judicial review, a maioria parlamentar reinante terá estímulos massivos para ignorar ações prévias da soberania popular, sempre que lhe seja conveniente" ${ }^{\prime 54}$. E, exatamente por isto, Bruce Ackerman, ao tratar de uma proposta para nova separação dos poderes, continua afirmando estar persuadido que "uma constituição deveria limitar o exercício da autonomia democrática protegendo direitos individuais fundamentais" $"$. Nesta linha de raciocínio, o argumento que simplesmente veda o controle de constitucionalidade com base no princípio formal da separação dos poderes é frágil, considerando a percepção de que "o parlamento também exercer poderes vinculados e de que a jurisdição constitucional, como órgão de poder, encontra seu fundamento na própria vontade constituinte" $" 56$.

Portanto, mesmo que se reconheça a possibilidade do estabelecimento de restrições implícitas (que não derivam diretamente do texto constitucional e tampouco são autorizadas por reserva expressa) pela legislação complementar ou ordinária, ainda assim é viável o controle de constitucionalidade da atividade legiferante (accountability), mediante a apreciação dos argumentos que embasaram o sopesamento de interesses fundamentais envolvidos, consoante critérios de proporcionalidade.

\section{CONCLUSÕES}

É recomendável a adoção do binômio composto pelas teorias ampla do suporte fático e externa das restrições, porquanto permitem maior plasticidade na conformação da norma para deliberação em casos concretos.

De acordo com tal combinação teórica (ampla/externa), é inconcebível uma norma jurídica que disponha sobre um direito fundamental sem implicar quaisquer restrições. Isto

53 HESSE, Konrad. Op. Cit. p. 66.

54 ACKERMAN, Bruce. A nova separação dos poderes. Rio de Janeiro: Lumen Juris, 2009. p. 41.

55 ACKERMAN, Bruce. Op. Cit. p. 106.

56 NASCIMENTO, Rogério José Bento Soares. Abuso do poder de legislar: controle judicial da legislação de urgência no Brasil e na Itália. Rio de Janeiro: Lumen Juris, 2004. p. 96. 
porque qualquer dispositivo supostamente de mera regulação acaba, invariavelmente, representando alguma restrição, ainda que em intensidade ínfima, ao direito fundamental respectivo ou a outros que com ele possam colidir.

Considerando tal premissa (inexistência de normas infraconstitucionais não-restritivas de direitos fundamentais), a resposta da indagação objeto do presente trabalho só pode ser positiva, no sentido de que a produção legislativa pode impor contornos aos direitos fundamentais, ainda que sem autorização constitucional expressa para tanto, estabelecendo as chamadas restrições implícitas. Ora, se toda norma que discipline direitos fundamentais envolve contenções em alguma amplitude ou extensão, negar ao congressista o poder de estabelecer restrições às faculdades essenciais quando não houver previsão constitucional acaba por acarretar, por vias oblíquas, uma limitação exacerbada ao exercício de sua função estatal precípua. Por isto, forçosa a ilação de que o parlamentar pode constituir novas restrições, além daquelas já eventualmente previstas diretamente (restrições diretas) ou facultadas (reserva legal para imposições restritivas) no texto fundamental.

Tal solução pode parecer problemática, porquanto confere ao congressista a faculdade de estabelecer contenções às prerrogativas essenciais sem autorização constitucional expressa. Todavia, sua atividade legiferante é controlável, porque somente é autorizada (ou seja, constitucionalmente válida), para fins de harmonização de interesses constitucionais contraditórios, observado o sopesamento por critérios de proporcionalidade.

Não se desconhece a existência de severas críticas ao sopesamento e, consequentemente, de análise da constitucionalidade de preceitos restritivos de direitos fundamentais. Porém, trata-se de uma alternativa viável ao paradigma positivista das discricionariedades parlamentar e judicial, desde que a ponderação esteja pautada por critérios argumentativos que permitam o diálogo intersubjetivo dos integrantes da sociedade. Com efeito, o sopesamento efetuado de acordo com a proporcionalidade e a técnica da precedência condicionada (dever de coerência) visa estabelecer parâmetros para aferição da sustentabilidade e racionalidade das medidas restritivas.

Portanto, uma das principais vantagens resultante da adoção conjugada das teorias ampla do suporte fático, externa das restrições e relativa da proteção do conteúdo essencial reside, precipuamente, na possibilidade do controle de constitucionalidade das medidas restritivas de direitos fundamentais de acordo com parâmetros de proporcionalidade, em face do ônus argumentativo que impõe, primeiro, ao legislador na fase de imposição da restrição e, posteriormente, ao magistrado quando se depara com o encargo de aferir a constitucionalidade da restrição. 


\section{REFERÊNCIAS}

ACKERMAN, Bruce. A nova separação dos poderes. Rio de Janeiro: Lumen Juris, 2009.

ALEXY, Robert. Constitucional rights, balancing and rationality. Ratio Juris, Oxford, v. 2, n. 2, p. 131-140, 2003.

On balancing and subsumption: A structural comparison. Ratio Juris, Oxford, v. 16, n. 4, p. 433-449, 2003.

Teoria dos direitos fundamentais. São Paulo: Malheiros, 2008.

ÁVILA, Humberto. Teoria dos princípios: Da definição à aplicação dos princípios jurídicos. 10 ed. São Paulo: Malheiros, 2009.

BARROS, Suzana de Toledo. O princípio da proporcionalidade e o controle de constitucionalidade das leis restritivas de direitos. 2 ed. Brasília: Brasília Jurídica, 2000.

CANOTILHO, José Joaquim Gomes. Direito constitucional e teoria da constituição. 7 ed. Coimbra: Almedina, 2003.

Estudos sobre direitos fundamentais. São Paulo: RT, 2009.

DWORKIN, Ronald. Levando os direitos a sério. 2 ed. São Paulo: Martins Fontes, 2007.

ECO, Umberto. Como se faz uma tese. 21 ed. São Paulo: Perspectiva, 2007.

HESSE, Konrad. Significado dos direitos fundamentais. In HESSE, Konrad. Temas fundamentais de direito constitucional. São Paulo: Saraiva, 2009. p. 23/72.

MENDES, Gilmar Ferreira. COELHO, Inocêncio Mártires. BRANCO, Paulo Augusto Gonet. Curso de direito constitucional. 3 ed. São Paulo: Saraiva, 2009.

MEZZAROBA, Orides. MONTEIRO, Cláudia Servilha. Manual de metodologia da pesquisa no direito. 3 ed. São Paulo: Saraiva, 2007.

MÜLLER, Friedrich. O novo paradigma do direito: Introdução à teoria e metódica estruturantes. 2 ed. São Paulo: RT, 2009.

Teoria estruturante do direito. V 1. São Paulo: RT, 2008.

NASCIMENTO, Rogério José Bento Soares. Abuso do poder de legislar: controle judicial da legislação de urgência no Brasil e na Itália. Rio de Janeiro: Lumen Juris, 2004.

PASOLD, César. Metodologia da comunicação nos trabalhos científicos. Florianópolis: Conceito Editorial, 2007. 2011.

- Metodologia da pesquisa jurídica: Teoria e prática. 12 ed. São Paulo: Conceito,

SCHÄFER, Jairo Gilberto. Direitos fundamentais: proteção e restrições. Porto Alegre: Livraria do Advogado, 2001.

SILVA, Virgílio Afonso da. Direitos fundamentais: Conteúdo essencial, restrições e 
eficácia. São Paulo: Malheiros, 2009. 2002 .

O proporcional e o razoável. Revista dos Tribunais, São Paulo, n. 798, p. 23/50,

ZANON JUNIOR, Orlando Luiz. Máxima da proporcionalidade aplicada: a quebra do sigilo bancário pelo Fisco e o direito fundamental à vida privada. Florianópolis: Momento Atual, 2004. 